\title{
Homesick: residential and care patterns in patients with severe mental illness
}

\author{
Liselotte D. de Mooij ${ }^{*}$, Martijn Kikkert ${ }^{1}$, Nick M. Lommerse' ${ }^{1}$, Jan Theunissen² ${ }^{2}$ Mariken B. de Koning ${ }^{3}$, \\ Lieuwe de Haan ${ }^{4}$, Aartjan T. F. Beekman ${ }^{5,6}$, Pim W. R. A. Duurkoop ${ }^{1}$ and Jack J. M. Dekker ${ }^{1,7}$
}

\begin{abstract}
Background: Changes in the residential and care settings of patients with severe mental illness (SMI) are a concern because of the large variety of possible negative consequences. This study describes patterns of changes in the residential and care settings of SMI patients and explores associations between these changes, sociodemographics, and clinical characteristics.
\end{abstract}

Methods: From January 2006 to January 2012, all data relating to changes in residential and/or care setting by SMI patients $(N=262)$ were collected from electronic case files. Data covering psychopathology, substance use, and medication adherence were assessed in 2006.

Results: There were more changes in the residential than in the care setting. In 6 years, only $22 \%$ of our sample did not move, 23\% changed residence once, 19\% twice, 10\% three times, and 26\% four or more times. Substance use predicted changes of care and/or residential setting and rehospitalisation. The severity of negative symptoms predicted rehospitalisation and duration of hospitalisation. Disorganisation symptoms predicted the duration of hospitalisation.

Conclusions: A majority of patients with SMI changed residential and/or care settings several times in 6 years. Patients with substance use or severe negative and disorganisation symptoms may need more intensive and customised treatment. Further research is needed to investigate prevention programmes for highly-frequent movers.

Keywords: Changes of residential setting, Changes of care setting, Changes in severe mental illness, Address changes, Hospitalisation, Revolving door

\section{Background}

The mental health-care system aims to allocate patients to the most appropriate house setting where they can stay for a long time. Although this seems straightforward, studies show that patients change address frequently [1-3]. Residential stability, the frequency in which one changes address, is an important determinant of quality of life in people with SMI and it is often a pre-condition for effective treatment and rehabilitation [4-6]. Instability in this domain is therefore stressful, and it can disrupt the continuity of treatment and cause social isolation $[4,7]$ or relapse $[8]$.

\footnotetext{
* Correspondence: Liselotte.de.Mooij@arkin.nl

${ }^{1}$ Arkin Research Department, Klaprozenweg 111, 1033 NN Amsterdam,

The Netherlands

Full list of author information is available at the end of the article
}

Residential changes are often a consequence of a change in care setting. Care setting refers to the type of care and can be generally divided into outpatient care for independently living patients, sheltered housing, and psychiatric admission. Changing from one care setting to another usually involves changing residence too. Allocating patients to another care setting is related to changing personal needs and abilities, but may also be associated with efforts to cut psychiatric beds in mental health care, which is an important goal in the Western world. Sheltered housing and outpatient care are used as alternatives to long-term psychiatric admission [9-12]. This is demonstrated by the fact that the Netherlands, with a population of 160,000 SMI patients, has 11,427 places in sheltered housing facilities and 18,499 in clinical care facilities $[13,14]$. The Netherlands therefore has 
much more intramural capacity than other Western countries [14].

Most SMI patients in Western countries live independently, either sharing a house with others such as relatives or a partner or living alone [15]. In general, patients who live independently receive outpatient treatment in an integrated approach comprising psychological and psychiatric treatment, and supported employment where possible. The primary treatment goals are the stabilisation of symptoms, preventing acute relapse and psychiatric hospitalisation, and improvements in social inclusion and structural activities. If independent housing is not feasible, SMI patients rely on residential care in sheltered housing. Sheltered housing often provides a range of housing options and care intensity [16]. If possible, patients are guided into independent housing; otherwise, the goal is to stabilise patients in long-term sheltered housing [17]. When sheltered housing is not an option, admission to a psychiatric hospital will be necessary. If these patients recover, independent housing or sheltered housing is encouraged [18].

Some studies have examined the risk factors for highly-frequent hospital admissions and discharges: "revolving door" cases [19]. The leading risk factors are being male [20], being younger [1, 21], substance abuse, and medication non-adherence $[19,22]$. However, there is a relative paucity of studies looking at the link between health and changes in the setting because of a lack of detailed information about health status and residential changes over time [23], particularly for patients with SMI [2]. Many studies have limited follow-up periods of only 2 years or less [5]. Furthermore, these studies often report the number of changes but failed to provide information about stay duration or longer-term patterns [1]. It is important to understand when and why the mental health-care system succeeds in providing patients with a stable home situation. A clearer picture will allow us to adapt our treatment and prevent frequent moves by SMI patients.

This study describes patterns of changes in care settings and in residential mobility in SMI patients over a follow-up period of 6 years. Secondly, we explored potential sociodemographics and clinical risk factors of (a) changes in care setting and (b) residential changes, (c) number and (d) total duration of psychiatric admissions. Hypotheses on patterns of change were based on policy and objectives of the different care settings, and on opinions of experts in this field such as clinicians and policy makers. This allowed us to specify the following patterns in care setting movements during the 6 years follow up period: (a) $25 \%$ of patients in sheltered housing will move to independent housing, (b) $65 \%$ of patients in sheltered housing will be long-term residents, and (c) $80 \%$ of inpatients will move to sheltered housing or to independent housing. Finally, we expected patients with more severe psychopathology and higher indices of substance use to be more likely to change residence and/or care setting more often. To the best of our knowledge, this is the first study to examine changes of residence, the relationship with the care setting and the associated determinants.

\section{Methods}

This longitudinal study conducted between 2005 and 2011 was based on a survey sample of SMI patients treated by the mental health-care institutions Arkin, GGZ InGeest, RIBW and HVO Querido in Amsterdam (Netherlands). These institutions are jointly responsible for the treatment of SMI patients residing in Amsterdam. The principal objectives of the study were to evaluate changes in quality of life, disease characteristics, general functioning, care needs, social networks and inclusion in society, and victimisation [24]. The current study is based on data relating to patient movements between 01/01/2006 and 01/01/2012. Data for severity of psychopathology, quality of life, substance use, and medication adherence were assessed at baseline in 2006. The study was approved by the Dutch Association of Medical-Ethical Appraisal Committees (NVMETC) for mental-health organisations.

\section{Population, inclusion and exclusion criteria}

Included patients fulfilled the criteria for a DSM-IV diagnosis of schizophrenia, psychotic disorder, substance use, severe mood or anxiety disorders and a history of intensive mental health care during the previous 2 years. Further inclusion criteria were: adequate mastery of Dutch or English and residence in the Amsterdam district for at least one year. Exclusion criteria included being unable to understand questions or communicate, or being unable or unwilling to give informed consent. Patients with comorbid substance use disorders were also included when they fulfilled these criteria [25]. The attending psychiatrist made the diagnoses.

\section{Enrolment}

In this study, 876 patients were randomly selected from 2846 patients treated by outpatient teams, or in sheltered housing facilities and inpatient care facilities. The aim was to include equal numbers of patients from the three care settings. A total of 553 patients $(63.1 \%)$ were not included in the study. Some patients refused to participate (25.9\%); others did not participate for unknown reasons (25.5\%). Another $2.9 \%$ of the patients were excluded because their clinicians deemed that inclusion would affect their clinical status. Patients who were no longer receiving treatment $(8.9 \%)$ were also excluded. 
The remaining 323 patients (37\% of the randomlyselected sample) were included in the study [24]. Once these patients had given written informed consent, the assessment was performed in a face-to-face interview. The interviews were conducted at the centre for mental health care or, if preferred by the patient, at the patient's home. The interview took one and a half hours and the patients received $€ 15$. The interviews were conducted by a trained psychologist, research assistants, and a senior researcher. The patients included were assessed again for the purposes of follow-up 6 years after inclusion.

\section{Measures}

Data about residential mobility and care setting came from electronic case files. Case notes were examined by a psychologist and a senior researcher to identify all address changes between 01/01/2006 and 01/01/2012, and all changes in care settings; living independently, sheltered housing and psychiatric hospital. Changes in the residential setting were defined as physical moves to another address, or a transfer to another department or ward within a housing facility such as a sheltered housing accommodation or a psychiatric hospital. Temporary moves, lasting less than 14 days, were not recorded as a change in address or care setting.

Patients can change address but remain in the same care setting. For instance, a patient may move from one sheltered housing facility to another. Moves of this kind were registered as a residence change but not as a change in care setting.

Severity of psychopathology was measured with the Brief Psychiatric Rating Scale-Expanded ('BPRS-E') $[26,27]$, which consists of 24 symptoms assessed on a scale from 1 to 7 . Items are grouped in four subscales - positive symptoms, negative symptoms, depression and disorganisation [27] - and scored on the basis of observations during the interview and patient self-reports. The BPRS-E is a sensitive instrument with good interrater reliability $(r=0.74, p<.001)$ and validity $[26,28,29]$.

Use of alcohol and drugs, substance dependence and abuse were assessed with the Measurements in the Addictions for Triage and Evaluation, or MATE [30], which assesses the use of psychoactive substances, lifetime and current substance abuse and dependence on the basis of DSM-IV [31]. The MATE is a valid instrument: inter-rater reliability ranges between 0.75 and 0.92 , and interviewer reliability ranges from 0.34 to 0.73 [30]. Patient files were also consulted to identify patients with a DSM-IV diagnosis of substance abuse or dependence. Patients were classified as having a dual diagnosis when the MATE indicated substance abuse or dependence or when a patient had already been diagnosed with a substance use disorder.
Medication adherence was assessed with the Medication Adherence Questionnaire (MAQ). The MAQ consists of four yes/no questions about ways in which patients may fail to take their prescribed medication: forgetting, carelessness, stopping the medication when they feel better and or stopping the medication because they believe it makes them feel worse [32]. Patients with a score $\leq 3$ on the MAQ were defined as non-adherent [32-34]. The MAQ is a valid and reasonable instrument for detecting non-adherence [32, 35].

\section{Data analysis}

Analyses were conducted using SPSS 22 (SPSS Inc., 2009). Frequency distributions were used to describe the data, chi-square analyses were used for categorical variables and ANOVA analyses were used to analyse continuous variables. When the expected cell count was too low to perform a chi-square test, Fisher's exact test was used. A Kruskal-Wallis test was used when ANOVA assumptions were violated and a Mann-Whitney test was used when $t$-test assumptions were violated. Generalised linear regression models (BACKSTEP method) were used to derive prediction models for the following three dependent variables: number of admissions, residential movements, and number of hospitalisation days. This analysis was considered appropriate since our data do not match the assumptions for multivariate linear regression models. The independent sociodemographic and clinical variables were age, gender, ethnicity, education, diagnosis, dual diagnosis, medication adherence, positive symptoms, negative symptoms, depression and anxiety, disorganisation, alcohol, cannabis, and hard drugs. Independent variables were removed stepwise during the statistical analyses when they did not contribute to the fit.

\section{Results}

The SMI cohort included 323 patients in 2006. In 2012, patient files were not available or incomplete for 49 patients. Data for six patients were not included because these patients were homeless for a longer period of time and another six patients were excluded because they did not give permission for the use of their patient files. As a result, complete data about residential and care setting changes were available for 262 patients. Patients were grouped into the categories 'living independently', 'sheltered housing' and 'psychiatric hospital' on the basis of their situation on 01-01-2006. In this sample, 100 patients were in a psychiatric hospital at baseline $(87 \%$ in a long-stay facility, $11 \%$ in a short-stay facility and $2 \%$ in an acute facility). Ninety per cent of the patients living in sheltered housing lived there with ten or more patients and only $10 \%$ lived with nine patients or fewer. 
Table 1 provides a summary of the main sociodemographic and clinical characteristics.

As expected, the different care settings differed $(P<.05)$ at baseline in terms of diagnosis, symptom severity, gender, education, diagnosis, cannabis and hard-drug use. However, standardised residual values showed no significant discrepancies for the different groups or for gender. Patients living independently were more highly educated than patients in a psychiatric hospital or sheltered housing $\left(\chi^{2}(4)=13.9\right)$, and these patients were also more likely to have mood disorders, anxiety disorders or axis II disorders than inpatients $\left(\chi^{2}(4)=7.5\right)$. Patients in sheltered housing were more often diagnosed with a dual diagnosis than patients living independently and patients in a psychiatric hospital $\left(\chi^{2}(2)=14.2\right)$. Inpatients had more severe positive $(H(2)=16.1)$, negative $(H(2)=49.9)$ and disorganisation $(\mathrm{H}(2)=41.9)$ symptoms and a higher total psychopathology score $(\mathrm{H}(2)=31)$ than patients living in sheltered housing or independently. Patients in sheltered housing had more days of cannabis $(\mathrm{H}(2)=9.8)$ and hard-drugs $(\mathrm{H}(2)=15.3)$ use in the past month than patients living independently and patients in a psychiatric hospital.

\section{Changes in care setting}

Patterns in changes of care setting during the six-year follow-up period were analysed to establish a clearer picture of how patients switch between different settings

Table 1 Socio-demographics, care facilities and clinical characteristics of the study sample $(N=262)$

\begin{tabular}{|c|c|c|c|c|c|c|c|}
\hline & \multicolumn{2}{|c|}{$\begin{array}{l}\text { Independent housing } \\
(n=103)\end{array}$} & \multicolumn{2}{|c|}{$\begin{array}{l}\text { Sheltered housing } \\
(n=59)\end{array}$} & \multicolumn{2}{|c|}{$\begin{array}{l}\text { Psychiatric hospital } \\
(n=100)\end{array}$} & $x^{2} / p^{a}$ \\
\hline \multicolumn{8}{|l|}{ Socio-demographics } \\
\hline Age, mean $(S D)$ & 46.1 & $(10)$ & 45.7 & $(10.5)$ & 43.8 & (11) & 0.261 \\
\hline \multicolumn{8}{|l|}{ Gender, $n(\%)$} \\
\hline Male & 53 & $(51.5)$ & 40 & $(67.8)$ & 69 & (69) & \multirow[t]{2}{*}{0.021} \\
\hline Female & 50 & $(48.5)$ & 19 & $(32.2)$ & 31 & (30) & \\
\hline \multicolumn{8}{|l|}{ Ethnicity, $n(\%)$} \\
\hline Western & 72 & $(69.9)$ & 30 & $(50.8)$ & 61 & (61.6) & \multirow[t]{2}{*}{0.055} \\
\hline Non-Western & 31 & $(30.1)$ & 29 & $(49.2)$ & 38 & $(38.4)$ & \\
\hline \multicolumn{8}{|l|}{ Education, $n(\%)^{b}$} \\
\hline Primary/secondary education & 72 & $(69.9)$ & 50 & $(84.7)$ & 82 & (82) & \\
\hline Higher education & 25 & $(24.3)$ & 8 & (13.6) & 8 & (8) & \multirow[t]{2}{*}{0.006} \\
\hline Unknown & 6 & $(5.8)$ & 1 & $(1.7)$ & 10 & (10) & \\
\hline \multicolumn{8}{|l|}{ Diagnosis, $n(\%)^{b}$} \\
\hline Schizophrenia and other psychotic disorders & 72 & $(69.9)$ & 49 & $(83.1)$ & 95 & (95) & \\
\hline Mood disorders/anxiety disorders/axis II disorders & 21 & $(20.4)$ & 3 & $(11.5)$ & 2 & $(7.7)$ & \multirow[t]{2}{*}{0.000} \\
\hline Substance use disorders & 10 & $(9.7)$ & 7 & $(11.7)$ & 3 & (3) & \\
\hline Comorbid substance use disorders, $n(\%)$ & 21 & $(20.4)$ & 27 & $(45.8)$ & 22 & (22) & $\leq 0.001$ \\
\hline Medication non-adherence & 38 & $(40)$ & 28 & (51.9) & 40 & (44) & 0.375 \\
\hline \multicolumn{8}{|l|}{ Symptoms (BPRS-E), mean $(S D)^{c}$} \\
\hline Positive symptoms & 1.6 & $(0.8)$ & 1.5 & (0.6) & 2.1 & $(1.0)$ & 0.000 \\
\hline Negative symptoms & 1.2 & $(0.3)$ & 1.3 & $(0.4)$ & 1.7 & $(0.7)$ & 0.000 \\
\hline Depression \& Anxiety & 1.8 & $(0.8)$ & 1.7 & $(0.6)$ & 2.0 & $(0.8)$ & 0.067 \\
\hline Disorganisation & 1.2 & $(0.2)$ & 1.3 & $(0.4)$ & 1.6 & (0.6) & 0.000 \\
\hline BPRS total & 1.4 & $(0.4)$ & 1.4 & $(0.4)$ & 1.8 & $(0.5)$ & 0.000 \\
\hline \multicolumn{8}{|l|}{ Substance use (MATE), mean (SD) ${ }^{c, d}$} \\
\hline Alcohol & 5.4 & $(10.2)$ & 8.5 & $(12.4)$ & 4.7 & (10) & 0.362 \\
\hline Cannabis & 2.3 & $(7.2)$ & 6.2 & (11.3) & 3.4 & (8.9) & 0.007 \\
\hline $\begin{array}{l}\text { Hard drugs (cocaine, stimulants, } \\
\text { 3,4-methylenedioxy- methamphetamine, opiates) }\end{array}$ & 1.7 & (7) & 5.1 & $(12.1)$ & 1.3 & $(7.1)$ & 0.001 \\
\hline
\end{tabular}

BPRS-E, Brief Psychiatric Rating Scale - Expanded; MATE Measurements in the Addictions for Triage and Evaluation

${ }^{a} P$ is the result of ANOVA for continuous variables and $X^{2}$ test for categorical variables. Significant findings at $P=0.05$ or less are shown in italics

${ }^{b}$ Expected cell count too low $(<5)$ for accurate chi-square, Fisher's exact test was performed

${ }^{\mathrm{C}}$ Assumptions of ANOVA were violated, Kruskal-Wallis test was performed. Number of days of substance use in the last month 
(Fig. 1). Patients were assigned to independent housing, sheltered housing, or psychiatric hospital groups on the basis of their situation on 01-01-2006. These three different settings were adopted as the starting point for every change. Residential changes within the same type of care setting were not included in these analyses. Some patients were admitted to general hospitals for somatic disorders $(n=30)$. These movements were not classified as changes in care setting.

We studied the movement patterns between three different types of care setting in each of the three groups described above. Patients who lived in one type of care setting throughout the follow-up period were considered stable. As clearly shown in Fig. 1, the patterns are similar in some of the groups described above: the group of patients switching between independent housing and a psychiatric hospital and patients switching between a psychiatric hospital and sheltered housing. Consequently, we conclude that there are six main patterns of changes in care setting: 1. living independently throughout the follow-up period, 2. sheltered housing, 3. a psychiatric hospital, 4. switching between a psychiatric hospital and living independently, 5. switching between psychiatric hospitals and sheltered housing and 6. moving from psychiatric hospitals to sheltered housing. Over a period of 6 years, half the patients stayed in the same care setting. Twenty-one per cent of SMI patients changed care setting once, $11 \%$ twice, $5 \%$ three times, and $14 \%$ four or more times.

Residential changes in were more frequent than changes in care setting: $78 \%$ changed address one or more times. Twenty-three per cent of patients with SMI changed address once, 19\% twice, 10\% three times and $26 \%$ four times or more. For each of the the six main patterns derived from Fig. 1, we looked at changesresidence, hospitalisation days, and number and type of admissions (Table 2). Patients moving back and forth between different care settings were included as a single group. These patients had the highest rates for residence changes, number of admissions and acute admissions.

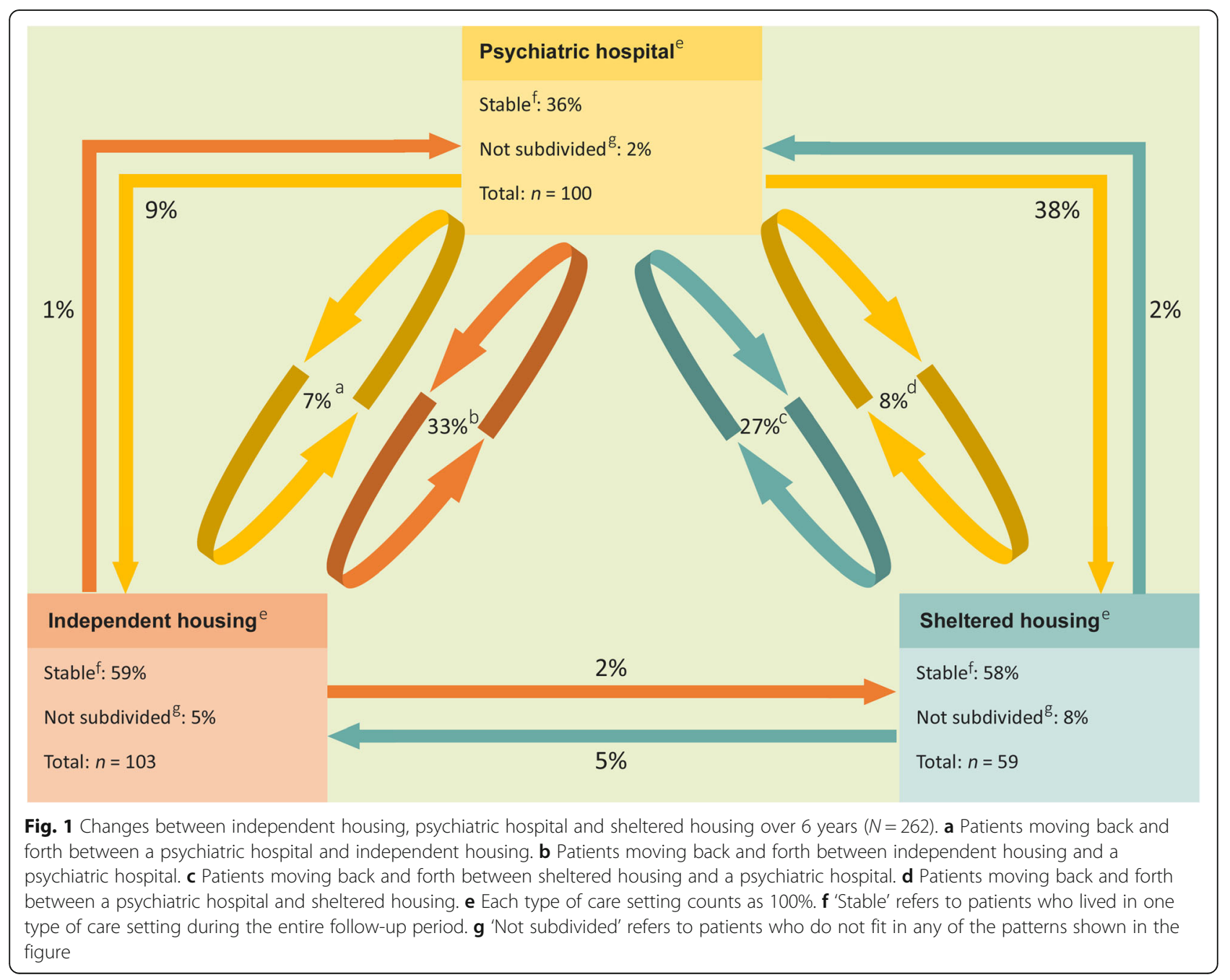


Table 2 Changes in residence, hospitalisation days, number and type of admissions over 6 years $(N=262)^{a}$

\begin{tabular}{|c|c|c|c|c|c|c|c|c|c|c|c|c|c|}
\hline & & \multicolumn{3}{|c|}{$\begin{array}{l}\text { Residential } \\
\text { changes }^{b}\end{array}$} & \multicolumn{3}{|c|}{$\begin{array}{l}\text { Number of } \\
\text { admissions }\end{array}$} & \multicolumn{3}{|c|}{ Hospitalisation days } & \multicolumn{3}{|c|}{ Type of admission ${ }^{c}$} \\
\hline & \multirow[b]{2}{*}{ N } & \multirow[b]{2}{*}{ Mean } & \multirow[b]{2}{*}{ Range } & \multirow[b]{2}{*}{ SD } & \multirow[b]{2}{*}{ Mean } & \multirow[b]{2}{*}{ Range } & \multirow[b]{2}{*}{ SD } & \multirow[b]{2}{*}{ Mean } & \multirow[b]{2}{*}{ Range } & \multirow[b]{2}{*}{$S D$} & \multirow{2}{*}{$\begin{array}{l}\text { Acute stay } \\
\%\end{array}$} & \multirow{2}{*}{$\begin{array}{l}\text { Short stay } \\
\%\end{array}$} & \multirow{2}{*}{$\begin{array}{l}\text { Long stay } \\
\%\end{array}$} \\
\hline & & & & & & & & & & & & & \\
\hline $\begin{array}{l}\text { Patients in independent housing } \\
\text { (stable pattern) }^{\mathrm{d}}\end{array}$ & 61 & 0.7 & $0-8$ & 1.4 & 0 & 0 & 0.0 & 0 & 0 & 0.0 & 0 & 0 & 0 \\
\hline $\begin{array}{l}\text { Patients in a psychiatric hospital } \\
\text { (stable pattern) }^{\text {d }}\end{array}$ & 36 & 2.9 & $0-8$ & 2.0 & 1.1 & $1-2$ & 0.3 & 1934 & 0 & 499.7 & 8.3 & 30.6 & 100 \\
\hline $\begin{array}{l}\text { Patients in sheltered housing } \\
\text { (stable pattern) }^{d}\end{array}$ & 34 & 0.9 & $0-2$ & 0.8 & 0 & 0 & 0.0 & 0 & 0 & 0.0 & 0 & 0 & 0 \\
\hline $\begin{array}{l}\text { Patients moving back and forth } \\
\text { between different care settings }\end{array}$ & 65 & 5.6 & $1-20$ & 4.1 & 2.7 & $1-8$ & 2.0 & 504.7 & $1-2076$ & 646.2 & 60 & 72.3 & 32.3 \\
\hline $\begin{array}{l}\text { Patients moving from psychiatric } \\
\text { hospitals to sheltered housing }\end{array}$ & 38 & 1.7 & $1-4$ & 1.0 & 1 & $1-2$ & 0.2 & 1365.1 & $318-2101$ & 516.0 & 5.3 & 2.6 & 100 \\
\hline $\begin{array}{l}\text { Patients moving from psychiatric } \\
\text { hospitals to independent housing }\end{array}$ & 9 & 1.8 & $1-2$ & 0.4 & 1.1 & $1-2$ & 0.3 & 1298.2 & 437-1977 & 531.8 & 57.1 & 100 & 100 \\
\hline All patients & 262 & 2.8 & $0-20$ & 3.4 & 1.1 & $0-8$ & 1.5 & 662.2 & $0-2191$ & 826.3 & 18.7 & 27.5 & 42.4 \\
\hline
\end{tabular}

${ }^{a}$ Changes in care setting affecting fewer than $6 \%$ of patients are not presented in this table

${ }^{\mathrm{b}}$ Moves to other address, changes in the type of care setting, or moves to another department in the same care setting were considered to be changes in the residential setting

'The percentages are the proportion of patients with acute admissions, or patients admitted for short or long stays in psychiatric hospitals

${ }^{d}$ 'Stable' refers to patients who spent the entire follow-up period in one type of care setting

To improve our understanding of which patients are more likely to change care setting and residence frequently, we performed four generalised linear model (GLM) analyses (Table 3) to predict changes in care setting, residential changes, number of admissions, and days in a psychiatric hospital. More frequent changes in the type of care setting were found in younger patients with a Western background and substance use in the last month. Patients with more admissions were younger and had a Western background, substance use disorders, and fewer negative symptoms. Finally, younger patients with fewer mood disorders/anxiety disorders or axis II disorders, with less medication non-adherence, with more negative and disorganisation symptoms, and with less alcohol and hard drugs use in the last month were more likely to stay longer in psychiatric care facilities.

\section{Discussion}

This study reports on unique data about patterns of changes in residential and care settings in SMI patients. Over a period of 6 years, 33\% of patients living independently switched from their own homes to a psychiatric hospital, and vice-versa. Twenty-seven per cent of patients in sheltered housing were admitted at least once to a psychiatric hospital, often for a short admission. Furthermore, $15 \%$ of the inpatients switched between psychiatric hospitals, independent and sheltered housing.

We hypothesized that $25 \%$ of patients in sheltered housing would move to independent housing during the 6 years follow-up. As can be seen in Fig. 1, only 5\% of patients made this move. The majority (65\%) of sheltered housed patients were expected to stay in sheltered homes. Although we found a slightly lower proportion of $58 \%$, our results confirm this hypothesis. We also hypothesized that $80 \%$ of patients in psychiatric hospitals would move to sheltered or independent housing. We found that only $47 \%$ of inpatients moved successfully to sheltered (38\%) or independent (9\%) housing.

The data yielded another important findings. We found patients who lived stably in independent housing (59\%), sheltered housing (58\%), or in psychiatric hospitals (36\%). However, over the period of 6 years we studied, half of the patients failed to achieve care stability, changing care setting one or more times. Residential changes were even more frequent: almost $80 \%$ moved one or more times and these patients had an average of almost six address changes in 6 years. This is in sharp contrast with the general population, which changes address an average of once every 10 years [36]. Those patients who moved back and forth between different care settings were most likely to change residence and to have the highest number of short admissions. Bearing in mind that an admission or an address change may disrupt the continuity of care, the unfortunate conclusion is that the patients most affected are precisely those for whom continuity of care is most important. However, many patients also have favourable, stable, housing patterns.

Our results indicate that only limited numbers of patients (5\%) move from sheltered to independent housing, contrary to the aims of the deinstitutionalisation process 
Table 3 Results of GLM analyses for predictors of changes in care setting, residential changes, number of admissions, and days in a psychiatric hospital between 01/01/2006 and 01/01/2012 ( $N=262)$

\begin{tabular}{|c|c|c|c|c|c|c|}
\hline & & & & & $95 \% \mathrm{Cl} \mathrm{fc}$ & \\
\hline & B & S.E. & P & Exp B & Lower & Upper \\
\hline Dependent factor: Changes in care setting ${ }^{a, 1}$ & & & & & & \\
\hline Included & & & & & & \\
\hline Age & -0.025 & 0.0082 & 0.002 & 0.975 & 0.960 & 0.991 \\
\hline Ethnicity & & & & & & \\
\hline Non-Western & -0.536 & 0.1784 & 0.003 & 0.585 & 0.412 & 0.830 \\
\hline Western & ref & & & & & \\
\hline Substance use disorders & 1.159 & 0.2722 & 0.000 & 3.188 & 1.869 & 5.435 \\
\hline Schizophrenia and other psychotic disorders & ref & & & & & \\
\hline Intercept & 1.603 & 0.3852 & 0.000 & 4.969 & 2.335 & 10.572 \\
\hline Dependent factor: Residential changes ${ }^{b, 2}$ & & & & & & \\
\hline Included & & & & & & \\
\hline Substance use disorders & 0.653 & 0.2582 & 0.011 & 1.921 & 1.158 & 3.186 \\
\hline Schizophrenia and other psychotic disorders & ref & & & & & \\
\hline Intercept & 0.936 & 0.0803 & 0.000 & 2.551 & 2.180 & 2.986 \\
\hline Dependent factor: Number of admissions ${ }^{3}$ & & & & & & \\
\hline Included & & & & & & \\
\hline Age & -0.023 & 0.0106 & 0.028 & 0.977 & 0.957 & 0.998 \\
\hline Ethnicity & & & & & & \\
\hline Non-Western & -0.566 & 0.2329 & 0.015 & 0.568 & 0.360 & 0.896 \\
\hline Western & ref & & & & & \\
\hline Substance use disorders & 0.977 & 0.3301 & 0.003 & 2.657 & 1.391 & 5.075 \\
\hline Schizophrenia and other psychotic disorders & ref & & & & & \\
\hline Negative symptoms (BPRS) & 0.453 & 0.1914 & 0.018 & 1.574 & 1.081 & 2.290 \\
\hline Intercept & -0.166 & 0.1492 & 0.265 & 0.847 & 0.632 & 1.135 \\
\hline Dependent factor: Days in psychiatric hospital ${ }^{4}$ & & & & & & \\
\hline Included & & & & & & \\
\hline Age & -0.014 & 0.0067 & 0.030 & 0.986 & 0.973 & 0.999 \\
\hline Mood disorders/anxiety disorders/axis II disorders & -0.943 & 0.2429 & 0.000 & 0.389 & 0.242 & 0.627 \\
\hline Schizophrenia and other psychotic disorders & ref & & & & & \\
\hline Medication non-adherence & -0.390 & 0.1576 & 0.013 & 0.677 & 0.497 & 0.922 \\
\hline Medication adherence & ref & & & & & \\
\hline Negative symptoms (BPRS) & 0.733 & 0.2077 & 0.000 & 2.081 & 1.385 & 3.127 \\
\hline Disorganisation & 0.581 & 0.1976 & 0.003 & 1.788 & 1.214 & 2.634 \\
\hline Alcohol & -0.003 & 0.0014 & 0.018 & 0.977 & 0.994 & 0.999 \\
\hline Hard drugs & -0.019 & 0.0041 & 0.000 & 0.981 & 0.973 & 0.989 \\
\hline Intercept & 5.569 & 0.4482 & 0.000 & 262.041 & 108.854 & 630.805 \\
\hline
\end{tabular}

${ }^{a}$ Changes of care setting include all moves between independent and sheltered housing, and psychiatric hospitals

${ }^{b}$ Moves to other address, or moves to another department or ward in the same care setting were considered to be changes in the residential setting

${ }^{\mathrm{C}} \mathrm{Cl}=$ confidence interval

${ }^{\mathrm{d}}$ Significant findings at $P=0.05$ or less are shown in italics

${ }^{1}$ Omnibus test; $P=0.000,{ }^{2}$ Omnibus test; $P=0.024,{ }^{3}$ Omnibus test; $P=0.001,{ }^{4}$ Omnibus test; $P=0.000$

[17]. This is a remarkable finding since the goal of sheltered housing has been to encourage patients to live as independently as possible. Given our data, it can be concluded that this goal is seldom achieved. One explanatory factor could be the shortage of affordable independent housing in Amsterdam. Another factor meriting consideration is the desirability of maximising the numbers of patients moving into independent housing: it is conceivable 
that forcing a patient to live independently without intensifying outpatient care could exacerbate a patient's condition.

After psychiatric admission, the majority of inpatients were expected to move (back) to independent housing or sheltered housing. There was indeed a relative large outflow (38\%) of patients from a psychiatric hospital to sheltered housing. Most of these patients came from long stay departments. Moving from a psychiatric hospital to independent housing seems more difficult and was observed a lot less than expected. Only 9\% of inpatients moved successfully to independent housing. Compared to inpatients who moved to sheltered housing, these patients came from an acute or short stay ward more often.

We found a relatively large group of patients living stably in psychiatric hospitals. This conflicts with the aims of deinstitutionalisation and is due to the fact that Amsterdam, although less than in other parts of the Netherlands, still has a relatively large number of psychiatric beds $[14,37]$. Instigated partly by changes in policy objectives, regulations and funding, there is now consensus among policy makers that mental health care should shift more towards placing the care of psychiatric patients in the community rather than in institutions. Therefore a national innovation programme has recently been developed to improve care of severe mental illness, recovery of health, participation and personal identity, and to help people with serious mental health issues catch up with the rest of society [38].

Furthermore, our data identified modifiable predictors for frequent care and residential changes. Substance use at baseline predicted both re-hospitalisation, changes in care setting and residential changes. In addition, more severe negative symptoms predicted re-hospitalisation and longer hospitalisation. Longer hospitalisation was predicted by more severe disorganisation. These results are consistent with other studies [3, 39-41]. Medication adherence and less substance use were predictors for longer hospitalisation. We think this is a spurious finding, since psychiatric hospitals provide more supervision and guidance in the areas of medication and the restriction of substance use. Our findings also showed that patients who failed to achieve stability were more frequently admitted to shortstay hospitals than to long-stay hospitals. Revolving-door patients may be admitted for shorter periods of time when substance use or medication non-adherence are the main cause of admission. When relief from acute intoxication or the regulation of medication are achieved, most patients will be ready to leave the hospital after a short period [19].

\section{Limitations}

This study had several limitations. First, the observational design means that we cannot demonstrate causation. The other issue is that we included only patients who receive psychiatric care; this may have resulted in the underestimation of the prevalence of changes. Moreover, we excluded patients who were homeless because we could not track them during the six-year study period. Homeless patients change care setting most frequently. More than half of the randomly selected patients were not included in our study. High dropouts are a common problem in studies with psychiatric patients and can reduce the external validity. We believe that those who were not included will generally be the more severely ill patients and they may change care and residential setting even more often. Furthermore, inpatients were over-represented in our sample group (38\%) by comparison with the general SMI population (13\%) [15]. Our results may therefore not be representative for the general SMI population. Despite our elaborate assessment of all changes in care and residential setting as registered in patient files, some patient files may have been incomplete. Incomplete information about addresses and accommodation status codes are a feature of routine clinical records [3].

\section{Conclusions and implications}

Our study shows that half the patients underwent multiple changes of care setting in 6 years. Approximately half the patients in each subgroup were stable in terms of the type of care setting. However, this does not mean that they always lived at the same address. Patients living stably in psychiatric hospitals and patients moving back and forth between different care settings changed residence most frequently.

Residential instability may be the consequence of how mental health care is usually organized. For each care setting different housing facilitites have been realized in most western countries. Consequently, if a patient's needs change and a different form of housing is required, one needs to move to another housing facility on another address. Approximately half of patients with schizophrenia will have an episodic course [42] which may result in many address changes over time. A care system which is able to provide a wider range of psychiatric and housing support on the same address, would make it possible for patients to stay in one place longer. There are some developments in this direction such as Intensive Home Treatment which allows patients to stay in their homes during crisis instead of being admitted to hospital [43].

Unstable residential and care patterns were predicted by substance use and the severity of negative symptoms. It is important to note that frequent moves are an underestimated stress factor and contribute to psychological instability. Adapting to new living conditions may contribute to stress, estrangement and an 
impoverishment of the social network [39]. Our secondary analysis did indeed confirm that patients with more re-hospitalisations had less frequent contact with people in their social network.

Given the ongoing process of deinstitutionalisation in most Western countries, we argue that more should be done to prevent unstable residential and care patterns in large groups of patients of the kind found in this study. Deinstitutionalisation should therefore be accompanied by flanking support programmes that can reduce the risk associated with frequent changes of care and residence. Our findings underline, for instance, the importance of integrating treatment and the prevention of substance use in treatment programmes.

Living independently is often seen as a desirable outcome in SMI patients but our results indicate that this aim should be reconsidered in some patients, who may be better off in sheltered housing. One could also argue that mental health care for those patients, who undergo highly frequent admissions and residential changes, needs improvement. This may imply that some patients need more support to live successfully in a stable situation. Future research should look at why the residential and care patterns of some patients are so turbulent and how we can help them to establish stable and safe homes.

\section{Abbreviations}

BPRS-E: The Brief Psychiatric Rating Scale-Expanded; GLM: Generalised linear model; MAQ: Medication Adherence Questionnaire; MATE: Addictions for Triage and Evaluation; SMI: Severe mental illness

\section{Acknowledgements}

The authors thank all patients and mental health workers for their participation in this study. We also thank Pim Duurkoop for his contribution to the data collection.

\section{Funding}

This study was supported by the Stichting tot Steun VCVGZ grants ST13102.Me2 (principal investigator, Dr. Jack Dekker).

\section{Availability of data and materials}

As our data contained personal addresses/postal codes and health locations, the raw data is not anonymous and might personally identify participants. Therefore, raw data will not be made publically available.

\section{Author's contributions}

Conceived the study: LD, MK, JD, MK, JT, MK, LH, AB, PD, JD. Designed the assessment: MK, JD, JT. Carried out the data acquisition: LD, NL, PD. Drafted the manuscript: LD. All authors read and approved the final manuscript.

\section{Competing interests}

The authors declare that they have no competing interests and they report no financial relationships with commercial interests.

\section{Consent for publication}

All participants also provided their consent for their de-identified data to be published.

\section{Ethics approval and consent to participate}

The study was approved by the Dutch Association of Medical-Ethical Appraisal Committees (NVMETC) for mental-health organisations. All participants were provided with a participant information sheet and provided their signed informed consent to participate in the study.

\section{Author details}

'Arkin Research Department, Klaprozenweg 111, 1033 NN Amsterdam, The Netherlands. ${ }^{2}$ GGZ inGeest Research Department, Arent Janszoon Ernststraat 1187, 1081 HL Amsterdam, The Netherlands. ${ }^{3}$ Arkin Department Mentrum, Baron G.A. Tindalstraat 27, 1019 TS Amsterdam, The Netherlands. ${ }^{4}$ Academic Medical Centre Department Early Psychosis, Meibergdreef 5, 1105 AZ Amsterdam-Zuidoost, The Netherlands. ${ }^{5}$ Vrije Universiteit Medical Centre Department Psychiatry, De Boelelaan 1117, 1081 HV Amsterdam, The Netherlands. ${ }^{6} \mathrm{GGZ}$ inGeest, Arent Janszoon Ernststraat 1187, $1081 \mathrm{HL}$ Amsterdam, The Netherlands. ${ }^{7}$ Vrije Universiteit Department Clinical Psychology, Van der Boechorststraat 1, 1081 BT Amsterdam, The Netherlands.

Received: 30 April 2016 Accepted: 22 November 2016

Published online: 03 December 2016

\section{References}

1. DeVerteuil G, Hinds A, Lix L, Walker J, Robinson R, Roos LL. Mental health and the city: intra-urban mobility among individuals with schizophrenia. Health Place. 2007;13:310-23.

2. Lix LM, Hinds A, DeVerteuil G, Robinson JR, Walker J, Roos LL. Residential mobility and severe mental illness: a population-based analysis. Adm Policy Ment HIth. 2006;33:160-71.

3. Sara GE, Burgess PM, Malhi GS, Whiteford HA, Hall WC. Stimulant and other substance use disorders in schizophrenia: Prevalence, correlates and impacts in a population sample. Aust Nz J Psychiat. 2014;48:1036-47.

4. Browne G, Hemsley M, St John W. Consumer perspectives on recovery: A focus on housing following discharge from hospital. Int J Ment Health Nurs. 2008;17:402-9.

5. Kreindler SA, Coodin S. Housing histories of assertive community treatment clients: program impacts and factors associated with residential stability. Can J Psychiatry. 2010;55:150-6.

6. Moxham LJ, Pegg SA. Permanent and stable housing for individuals living with a mental illness in the community: A paradigm shift in attitude for mental health nurses. Austra Nz J Ment Health Nurs. 2009;9:82-8.

7. Abood Z, Sharkey A, Webb M, Kelly A, Gill M. Are patients with bipolar affective disorder socially disadvantaged? A comparison with a control group. Bipolar Disord. 2002;4:243-8.

8. Lamont A, Ukoumunne OC, Tyrer P, Thornicroft G, Patel R, Slaughter J. The geographical mobility of severely mentally ill residents in London. Soc Psychiatry Psychiatr Epidemiol. 2000;35:164-9.

9. Dekker JJM, Van den Langenberg SJAM. Trends in mental health care in Amsterdam. Psychiatr Serv. 1994;45:494-6.

10. Priebe S, Saidi M, Want A, Mangalore R, Knapp M. Housing services for people with mental disorders in England: patient characteristics, care provision and costs. Soc Psychiatry Psychiatr Epidemiol. 2009;44:805-14.

11. Rogers ES, Kash-MacDonald M, Olschewski A. Systematic review of supported housing literature 1993-2008. Boston: Boston University, Sargent College, Center for Psychiatric Rehabilitation; 2009.

12. van Hoof F, van Vugt M, Knispel A, Kroon H. Bedden tellen: afbouw van de intramurale GGZ [Counting beds: reducing the intramural capacity in mental health care]. Het Maandblad Geestelijke volksgezondheid. 2012;67:298-309.

13. Delespaul PH, En de Consensusgroep EPA. Consensus over de definitie van mensen met een ernstige psychische aandoening (epa) en hun aantal in Nederland. [Consensus about the definition of people with a severe mental illness (SMI) and their prevalence in the Netherlands]. Tijdschr Psych. 2013;55:427-38.

14. van Dijk S, Knispel A, Nuijen J. GGZ in tabellen 2009. [Tables of mental health care in 2009]. Utrecht: Trimbos-instituut, Netherlands Institute of Mental Health and Addiction; 2010.

15. de Ruiter KGC, van Greuningen M, van Gerwen L. Zorgthermometer Transparantie in de geestelijke gezondheidszorg [Care thermometer, Transparency in mental health care]. Zeist: Vektis; 2015.

16. van Hoof F, Knispel A, Schneider J, Beeley C, Aagaard J, van Putten M, et al. Outpatient care and community support for persons with severe mental health problems. A comparison of national policies and systems in Denmark, England and the Netherlands. Utrecht: Trimbos instituut; Netherlands institute of Mental Health and Addiction; 2011.

17. Janssen M, Klankbordgroep GGZ Amsterdam. Het Amsterdamse Model Halfweg. Een tussenstand van de GGZ-hervormingen in de hoofdstad [The Model of Amsterdam Halfweg. An intermediate position of the mental health reformations in the capital]. Utrecht: Nederlands centrum Geestelijke volksgezondheid; 1993. 
18. Sharfstein SS. Goals of inpatient treatment for psychiatric disorders. Annu Rev Med. 2009;60:393-403.

19. Haywood TW, Kravitz HM, Grossman LS, Cavanaugh Jr JL. Predicting the" revolving door" phenomenon among patients with schizophrenic, schizoaffective, and affective disorders. Am J Psychiatry. 1995;152:856-61.

20. Mahendran R, Chong SA, Chan YH. Brief communication: factors affecting rehospitalisation in psychiatric patients in Singapore. Int J Soc Psychiatry. 2005:51:101-5.

21. Tulloch AD, Fearon P, Fahy T, David A. Residential mobility among individuals with severe mental illness: cohort study of UK700 participants. Soc Psychiatry Psychiatr Epidemiol. 2010;45:767-77.

22. Csernansky JG, Schuchart EK. Relapse and rehospitalisation rates in patients with schizophrenia. CNS drugs. 2002;16:473-84.

23. Larson A, Bell M, Young AF. Clarifying the relationships between health and residential mobility. Soc Sci Med. 2004;59:2149-60.

24. Dekker JJ, Theunissen J, Van R, Peen J, Duurkoop P, Kikkert M. Victimization of patients with severe psychiatric disorders: prevalence, risk factors, protective factors and consequences for mental health.A longitudinal study. BMC publ HIth. 2010;10:687.

25. Dubbele Diagnose, Dubbele Hulp-Richtlijnen voor Diagnostiek en Behandeling, Dubbele Hulp-Richtlijnen voor Diagnostiek en Behandeling. Rapport project Dubbele Diagnose door Verslavingszorg Parnassia [Dual Diagnosis, Dual Guidelines for diagnostics and treatment. Report project Dual Diagnosis by addiction care Parnassia]. Psycho-medisch centrum Den Haag [Psycho medical centre Den Hague]. 2003.

26. Andersen J, Larsen JK, Schultz V, Nielsen BM, Korner A, Behnke K, et al. The brief psychiatric rating scale. Psychopathology. 1989;22:168-76.

27. Ruggeri M, Koeter M, Schene A, Bonetto C, Vázquez-Barquero JL, Becker T, et al. Factor solution of the BPRS-expanded version in schizophrenic outpatients living in five European countries. Schizophr Res. 2005;75:107-17.

28. Kopelowicz A, Ventura J, Liberman RP, Mintz J. Consistency of Brief Psychiatric Rating Scale factor structure across a broad spectrum of schizophrenia patients. Psychopathology. 2008;41:77-84.

29. Overall JE, Rhoades M. Refinement of phenomenological classification in clinical psychopharmacology research. Psychopharmacology. 1982;77:24-30.

30. Schippers GM, Broekman TG, Buchholz A, Koeter MW, Van Den Brink W. Measurements in the Addictions for Triage and Evaluation (MATE): an instrument based on the World Health Organization family of international classifications. Addiction. 2010;105:862-71.

31. Schippers GM, Broekman TG, Buchholz A. Manual and protocol for assessment, scoring and use of the MATE 2.1. Nijmegen: Bureau Beta; 2011.

32. Morisky DE, Green LW, Levine DM. Concurrent and predictive validity of a self-reported measure of medication adherence. Med Care. 1986;24:67-74.

33. George CF, Peveler RC, Heiliger S, Thompson C. Compliance with tricyclic antidepressants: the value of four different methods of assessment. $\mathrm{Br} \mathrm{J}$ Clin Pharmacol. 2000;50:166-71.

34. Roth MT, Ivey JL. Self-reported medication use in community-residing older adults: a pilot study. Am J Geriatr Pharmac. 2005;3:196-204.

35. Shalansky SJ, Levy AR, Ignaszewski AP. Self-reported Morisky score for identifying nonadherence with cardiovascular medications. Ann Pharmacother. 2004;38:1363-8.

36. Planbureau voor de Leefomgeving. http://tinyurl.com/migrationanda ddresschanges. Accessed 11 Nov 2015.

37. Dekker J, Theunissen J, Van R, Kikkert M, van der Post L, Zoeteman J, Peen J. Are long-term psychiatric patients causing more crisis consultations outside office hours in mental health care? Int J Soc Psychiatry. 2013;59:555-60.

38. Crossing the bridge. A national action plan to improve care of severe mental illness. Utrecht: Couwenbergh C, van Weeghel J. Kenniscentrum Phrenos; 2014.

39. Herbener ES, Harrow M. Are negative symptoms associated with functioning deficits in both schizophrenia and nonschizophrenia patients? A 10-year longitudinal analysis. Schizophr Bull. 2004;30:813-25.

40. Kelly A, Watson D, Raboud J, Bilsker D. Factors in delays in discharge from acute-care psychiatry. Can J Psychiatry. 1998;43:496-501.

41. Langdon E. Who walks through the 'revolving-door' of a British psychiatric hospital? J Mint Health. 2001;10:525-33.

42. Wiersma D, Nienhuis FJ, Slooff CJ, Giel R. Natural course of schizophrenic disorders: a 15-year followup of a Dutch incidence cohort. Schizophr Bull. 1998:24(1):75-85.

43. Murphy SM, Irving CB, Adams CE, Waqar M. Crisis intervention for people with severe mental illnesses. Cochrane Database Syst Rev. 2015;12: CD001087. doi:10.1002/14651858.

\section{Submit your next manuscript to BioMed Central and we will help you at every step:}

- We accept pre-submission inquiries

- Our selector tool helps you to find the most relevant journal

- We provide round the clock customer support

- Convenient online submission

- Thorough peer review

- Inclusion in PubMed and all major indexing services

- Maximum visibility for your research

Submit your manuscript at www.biomedcentral.com/submit 